\title{
MORE EFFICIENT CHASSIS PARTS
}

Ultra light and cost-optimized damper tubes, lighter and even more compact vehicle springs plus a new, integrated variable damping system: these are just some of the innovations with which ThyssenKrupp is achieving increased vehicle component efficiency and performance. Today, OEMs expect to be able to integrate these components into increasingly complex systems. In addition to lightweight design and function optimization, development activities are therefore also focused on optimal package design and compatibility with active, networked chassis systems.

000

000

000

200

3000

000

000

00

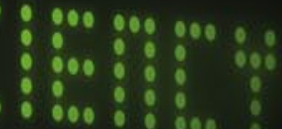

- 000:800. 